\title{
Challenges in the management of Wilms Tumor in a developing country: A twenty years experience from a single centre in Pakistan.
}

\author{
Muhammad Khan ${ }^{1}$, Ata Maaz ${ }^{2}$, and Muhammad Ashraf ${ }^{3}$ \\ ${ }^{1}$ King Faisal Specialist Hospital and Research Center, Madinah \\ ${ }^{2}$ Sidra Medical and Research Center \\ ${ }^{3}$ The Indus Hospital
}

May 26, 2021

\begin{abstract}
Background: Wilms Tumour (WT) is one of the most curable childhood cancers. High cure rates seen in the high-income countries are not duplicated in low and middle-income countries due to several constraints. We reviewed our data over the last 20 years in order to highlight some of these challenges. Methods: This is a retrospective review of medical notes of children with WT under the age of 18 years presenting to our institution between 1 November 1997 and 30 November 2017. Demographic, presentation and treatment details were recorded and factors associated with poor outcome were analysed. Results: Of the 211 children presenting with WT 117(55.5\%) were males. Median age at presentation was 3 (Range 0-18) years. One hundred and twelve $(53.7 \%)$ of these presented without any prior treatment, while $72(34.1 \%)$ presented after tumour excision. Metastatic status was available for 178 patients; 117 (68\%) had localised tumours, 36(21.8\%) had metastatic disease and 25(11.9\%) presented with recurrent mass. Thirty-nine (18.4\%) patients refused treatment and $6(2.8 \%)$ died before starting treatment. During treatment, 23(13.4\%) children died and 21(12.2\%) abandoned. Only 99 patients finished treatment, 83 (83.8\%) of whom are well off therapy and $15(15.2 \%)$ have relapsed. Six (40\%) of the 15 children who relapsed are alive after salvage therapy, while the remaining $9(60 \%)$ have died. Conclusions: Our data highlights the challenges of managing WT in resource poor environments. Prior surgery, incomplete staging work-up and abandonment are some of the most frequently encountered barriers. A multipronged approach is required to overcome these challenges.
\end{abstract}

TITLE: Challenges in the management of Wilms Tumor in a developing country: A twenty years experience from a single centre in Pakistan.

Author 1

NAME: Muhammad Rahil Khan

ADDRESS: Department of Paediatric Haematology/ Oncology, King Faisal Specialist Hospital, Al Madina al Munawara, Saidi Arabia

Author 2: Corresponding author:

NAME: Ata Ur Rehman Maaz

ADDRESS: Department of Pediatrics, division of Haematology/Oncology, Sidra Medicine, Al-Luqta Street, P.O. Box 26999, Doha, Qatar

Email: amaaz@sidra.org

PHONE: +974 40036591

FAX: 
Author 3:

NAME: Muhammad Shamvil Ashraf

ADDRESS: Department of Paediatric Haematology/ Oncology, Indus Hospital and Health Network, Karachi, Plot C-76, Sector 31/5, Opposite Darussalam Society, Korangi Crossing, Karachi 75190, Pakistan

Email: Muhammad.shamvil@gmail.com

Word count: Abstract: 250

Main text: 3186

Number of tables: 2

Number of Figures: 3

No supporting information file

Short Running Title: Challenges of managing Wilms Tumor in Pakistan

Key words: Wilms Tumour, Nephroblastoma, Abandonment, Challenges, Barriers

Abbreviation Key:

\begin{tabular}{ll}
\hline Abbreviation & Key \\
\hline WT & Wilms Tumor \\
NWTSG & National Wilms Tumor Study Group \\
COG & Children's Oncology Group \\
SIOP & International Society of Paediatric Oncology \\
HIC & high income countries \\
LMIC & Low and middle income countries \\
ASIR & Age standardised incidence rate \\
IRB & Institutional review board \\
Gy & Gray \\
OS & Overall survival \\
EFS & Event free survival \\
SMN & second malignant neoplasms \\
SPSS & Statistical package for social sciences \\
\hline
\end{tabular}

\section{Hosted file}

PBC WT manuscript 5521[1].docx available at https://authorea.com/users/415905/articles/ 523654-challenges-in-the-management-of-wilms-tumor-in-a-developing-country-a-twentyyears-experience-from-a-single-centre-in-pakistan

\section{Hosted file}

PBC WT TABLE 1 .docx available at https://authorea.com/users/415905/articles/523654challenges-in-the-management-of-wilms-tumor-in-a-developing-country-a-twenty-yearsexperience-from-a-single-centre-in-pakistan

\section{Hosted file}

PBC WT TABLE 2 .docx available at https://authorea.com/users/415905/articles/523654challenges-in-the-management-of-wilms-tumor-in-a-developing-country-a-twenty-yearsexperience-from-a-single-centre-in-pakistan

\section{Hosted file}


Figure 1 Final.docx.pdf available at https://authorea.com/users/415905/articles/523654challenges-in-the-management-of-wilms-tumor-in-a-developing-country-a-twenty-yearsexperience-from-a-single-centre-in-pakistan

Figure 2: Kaplan-Meier estimates of overall and event free survival for all patients with Wilms Tumour

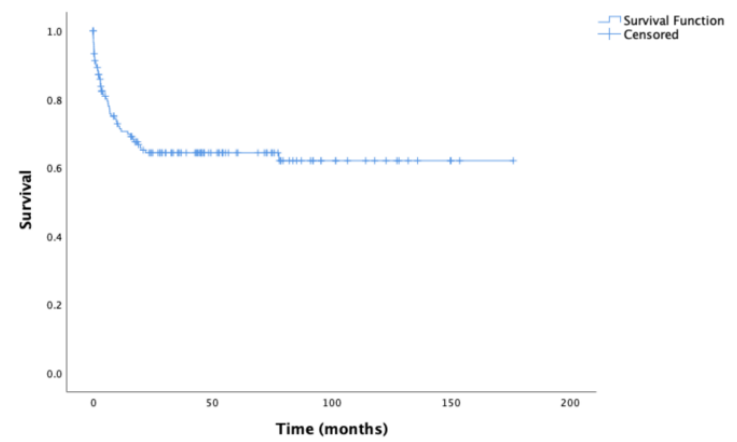

A: Overall survival (OS): 66.7\% after median follow-up of 113 (range 99-127) months.

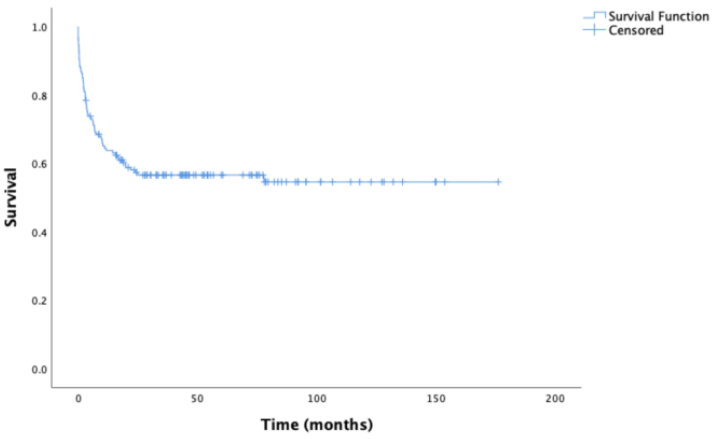

Figure 2B: Event free survival (EFS): 56.9\% after median follow-up of 100 (range 86-114) months. 
Figure 3: Determinants of poor outcome for Wilms Tumour in low and middle income countries (LMIC).

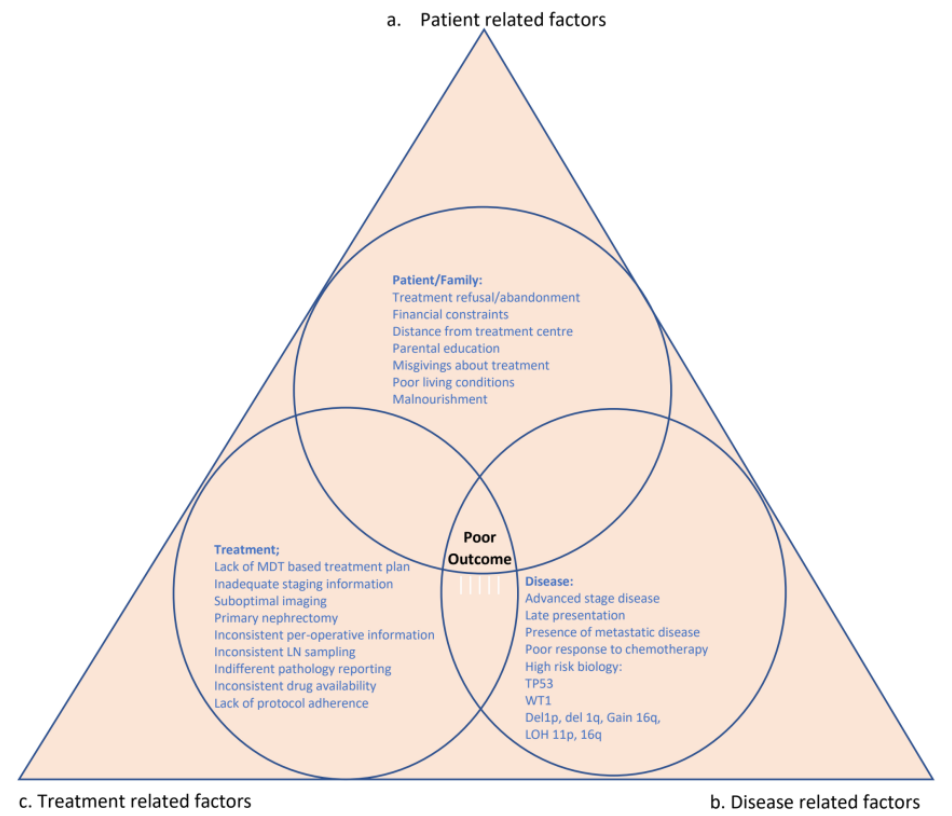

Figure 3: Poor outcome for WT is a result of interplay between (a) patient-related, (b) disease-related and (c) treatment-related factors, which are inter-dependant and not mutually exclusive. 